\title{
Minimum effective volume of mepivacaine for ultrasound- guided supraclavicular block
}

\author{
Jae Gyok Song, Dae Geun Jeon, Bong Jin Kang, and Kee Keun Park \\ Department of Anesthesiology and Pain Medicine, College of Medicine, Dankook University, Cheonan, Korea
}

Background: The aim of this study was to estimate the minimum effective volume (MEV) of $1.5 \%$ mepivacaine for ultrasound-guided supraclavicular block by placing the needle near the lower trunk of brachial plexus and multiple injections.

Methods: Thirty patients undergoing forearm and hand surgery received ultrasound-guided supraclavicular block with 1.5\% mepivacaine. The initial volume of local anesthetic injected was $24 \mathrm{ml}$, and local anesthetic volume for the next patient was determined by the response of the previous patient. The next patient received a $3 \mathrm{ml}$ higher volume in the case of the failure of the previous case. If the previous block was successful, the next volume was 3 ml lower. MEV was estimated by the Dixon and Massey up and down method. MEV in 95, 90, and 50\% of patients $\left(\mathrm{MEV}_{95}, \mathrm{MEV}_{90}\right.$, and $\mathrm{MEV}_{50}$ ) were calculated using probit transformation and logistic regression.

Results: $\mathrm{MEV}_{95}$ of $1.5 \%$ mepivacaine was $17 \mathrm{ml}$ (95\% confidence interval [CI], 13-42 ml), $\mathrm{MEV}_{90}$ was $15 \mathrm{ml}$ (95\% CI, 12-34 ml), and $\mathrm{MEV}_{50}$ was $9 \mathrm{ml}(95 \% \mathrm{CI}, 4-12 \mathrm{ml})$. Twelve patients had a failed block. Three patients received general anesthesia. Nine patients could undergo surgery with sedation only. Only one patient showed hemi-diaphragmatic paresis.

Conclusions: $\mathrm{MEV}_{95}$ was $17 \mathrm{ml}, \mathrm{MEV}_{90}$ was $15 \mathrm{ml}$, and $\mathrm{MEV}_{50}$ was $9 \mathrm{ml}$. However, needle location near the lower trunk of brachial plexus and multiple injections should be performed. (Korean J Anesthesiol 2013; 65: 37-41)

Key Words: Mepivacaine, Minimum effective volume, Supraclavicular block, Ultrasound.

Received: November 7, 2012. Revised: November 30, 2012. Accepted: December 10, 2012.

Corresponding author: Dae Geun Jeon, M.D., Department of Anesthesiology and Pain Medicine, College of Medicine, Dankook University, Anseo-dong, Cheonan 330-715, Korea. Tel: 82-41-550-6829, Fax: 82-41-551-9330, E-mail: timepain@hanmail.net

(c) This is an open-access article distributed under the terms of the Creative Commons Attribution Non-Commercial License (http:// creativecommons.org/licenses/by-nc/3.0/), which permits unrestricted non-commercial use, distribution, and reproduction in any medium, provided the original work is properly cited. 


\section{Introduction}

Ultrasound-guided supraclavicular block provides reliable analgesia for upper limb surgery [1]. This technique also has higher success rates, faster onset, and fewer complications than conventional techniques $[1,2]$. However, the possibility of reduced volume for an effective block was in doubt $[3,4]$, whereas reduction in volume was possible in other peripheral regional blocks with ultrasound guidance [5-8].

The trials for reducing local anesthetic volume have failed in ultrasound-guided supraclavicular blocks using the Dixon and Massey up and down method (DUDM) and biased coin design up and down method (BUDM) [3,4]. By contrast, Bigeleisen et al. [9] achieved $100 \%$ of success rate with $20 \mathrm{ml}$ of local anesthetic in ultrasound-guided supraclavicular block. However, their result were from intraneural injection, which could lead to neurological complications $[10,11]$.

Therefore, the aim of this study was to estimate the minimum effective volume (MEV) of $1.5 \%$ mepivacaine for ultrasoundguided supraclavicular block by introducing the needle near the lower trunk of brachial plexus and multiple injections.

\section{Materials and Methods}

After Institutional Review Board approval and patient written informed consent was obtained, thirty patients (American Society of Anesthesiologists physical status I and II) undergoing forearm and hand surgery received ultrasound-guided supraclavicular block with $1.5 \%$ mepivacaine.

All blocks were performed by a single experienced operator and a single experienced assistant. An ultrasound machine

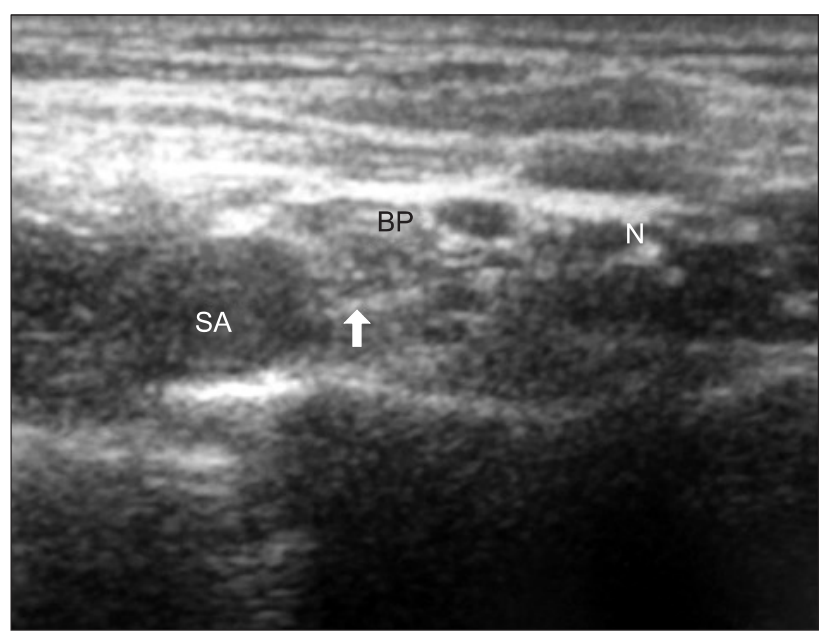

Fig. 1. Ultrasound image in ultrasound-guided supraclavicular block. SA: subclavian artery, BP: brachial plexus, N: needle, $\uparrow$ (arrow) needle tip.
(Vivid $\mathrm{I}^{\circledR}$, GE Yokogawa Medical Systems Ltd., Tokyo, Japan) and a $12 \mathrm{MHz}$ linear type probe were used. The supraclavicular fossa was scanned to locate the subclavian artery and brachial plexus cluster in a sterile fashion. A skin wheal was raised with $2 \mathrm{ml}$ of $2 \%$ lidocaine. Using an in-plane technique, a 22 gauge, $5 \mathrm{~cm}$, short beveled insulated needle (Stimuplex ${ }^{\circledR} \mathrm{D}, \mathrm{B}$. Braun, Melsungen AG, Japan) was advanced from the lateral to medial. The needle was advanced and withdrawn repeatedly in zigzags to avoid nerve puncture until the needle tip was located near the lower trunk of brachial plexus during the approach (Fig. 1). Then it was confirmed that the location of the needle tip was not in hypoechoic nodules (in nerves) to avoid intraneural injection. For further safety, $0.5 \mathrm{ml}$ of local anesthetic was injected as a test dose. If patients did not complain of paresthesia or pain, or injection pressure was not high, the remaining dose of local anesthetic was injected incrementally while withdrawing the needle.

The first patient received $24 \mathrm{ml}$ of local anesthetic. This volume was derived from the $\mathrm{MEV}_{50}(23 \mathrm{ml})$ in Duggan et al. [3] . Local anesthetic volume for the next patient was determined by the response of the previous patient. The next patient received a $3 \mathrm{ml}$ higher volume in the case of the failure of the previous case. If the previous block was successful, the next volume was 3 $\mathrm{ml}$ lower.

Data were collected by an assessor blinded to the patient's volume assignments. The extent of sensory blockade was tested in all five nerve distributions (musculocutaneous nerve: lateral side of the forearm, radial nerve: dorsum of the hand over the 2nd metacarpophalangeal joint, ulnar nerve: little finger, median nerve: medial thenar eminence, and medial cutaneous nerve: medial side of the forearm) using pin prick test with 26 gauge needle: $0=$ no perception, $1=$ decreased sensation, or $2=$ normal sensation. Successful blockade was defined as complete sensory blockade (sensory block score $=0$ in all five terminal nerve distributions) in the distribution of five terminal nerves at 30 minutes after local anesthetic injection.

Patients' complications such as Horner's sign, voice change and chest discomfort (dyspnea) were also checked at this time. A post-block chest X-ray was obtained to check for hemidiaphragmatic paralysis or pneumothorax postoperatively. Furthermore, neurological complications were evaluated by a surgeon when the patients revisited (about 1-1.5 month after operation). The patients with failed blockades had general anesthesia or sedation with midazolam. An additional block was not performed due to time limitation.

Statistical analysis was performed with SPSS version 12 (SPSS, Inc. Chicago, IL, USA). Sample size was determined by referring to the previous studies $[1,2,12-15]$ using the formula $(2[\mathrm{SD} /$ $\left.\mathrm{SE}]^{2}\right)[16,17]$. Only failures were used and analyzed using probit transformation and logistic regression to calculate MEV. 


\section{Results}

Patient characteristics are presented in Table 1. Fig. 2 depicts the sequence of successful and unsuccessful supraclavicular blocks. The $\mathrm{MEV}_{95}, \mathrm{MEV}_{90}$, and $\mathrm{MEV}_{50}$ of $1.5 \%$ mepivacaine were $17 \mathrm{ml}$ (95\% confidence interval [CI], 13-42 ml), $15 \mathrm{ml}(95 \%$ $\mathrm{CI}, 12-34 \mathrm{ml})$, and $9 \mathrm{ml}$ (95\% CI, 4-12 ml), respectively.

Twelve patients had a failed block. Three patients received general anesthesia. Nine patients did not require supplementary, as surgical anesthesia had been adequately achieved in the anatomic distribution of the proposed surgery.

Seven patients showed Horner syndrome (23.3\%). No patient showed voice change, only one patient complained of dyspnea, and showed hemi-diaphragmatic paresis on the postoperative chest X-ray (Table 2). No neurological complications were observed.

\section{Discussion}

In the anesthetic field, DUDM has been used to estimate minimum alveolar concentration of inhalational anesthetic agents $[18,19]$. One of the advantages of the DUDM is a smaller sample size required to estimate the ED50 and a simple study design $[16,17]$.

Using the DUDM, we found that the $\mathrm{MEV}_{95}, \mathrm{MEV}_{90}$, and $\mathrm{MEV}_{50}$ of $1.5 \%$ mepivacaine for ultrasound-guided supra-

Table 1. Patient Characteristics

$\begin{array}{lc}\text { Age }(\mathrm{yr}) & 43.4 \pm 17.0 \\ \text { Sex }(\mathrm{M} / \mathrm{F}) & 18 / 12 \\ \text { Height }(\mathrm{cm}) & 165.3 \pm 8.3 \\ \text { Weight }(\mathrm{kg}) & 65.5 \pm 11.9 \\ \text { BMI }\left(\mathrm{kg} / \mathrm{m}^{2}\right) & 23.9 \pm 3.5\end{array}$

Number of patients or mean \pm SD. BMI indicates body mass index.

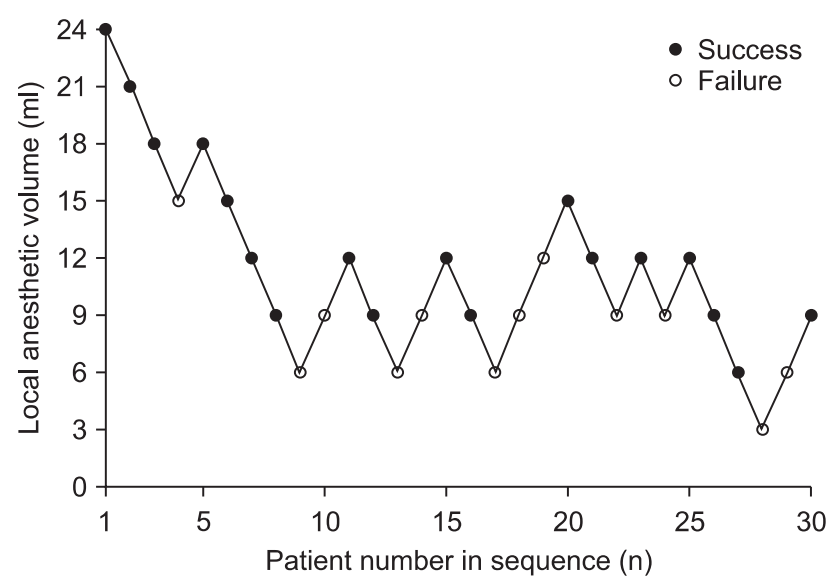

Fig. 2. Up and down sequence of ultrasound-guided supraclavicular block. clavicular block were $17 \mathrm{ml}$ (95\% CI, 13-42 ml), $15 \mathrm{ml}$ (95\% CI, 12-34 ml), and $9 \mathrm{ml}$ (95\% CI, 4-12 ml), respectively. These results are comparable with previous studies using up and down methods (DUDM and BUDM) [3,4]. Those studies estimated $\mathrm{MEV}_{95}, \mathrm{MEV}_{90}$, and $\mathrm{MEV}_{50}$ values for local anesthetic as $42 \mathrm{ml}$, $32 \mathrm{ml}$, and $23 \mathrm{ml}$, respectively [3,4]. Therefore, they concluded that ultrasound-guided supraclavicular block could not reduce the volume of local anesthetic for effective block. However, our results showed that ultrasound-guided supraclavicular block could reduce the local anesthetic volume as same as other peripheral nerve blocks with ultrasound guidance [5-8].

In conventional technique for ultrasound-guided supraclavicular block, the needle is advanced in plane toward the brachial plexus, in a lateral to medial direction. Once the needle is entered into the sheath, the small amount of local anesthetic is injected. When the spread of local anesthetic is visualized in the sheath, the rest of local anesthetic is injected until the local anesthetic is around and in the brachial plexus [20]. In this situation, divisions from lower trunk are frequently spared, and more local anesthetic volume is needed to reach the lower trunk and its divisions.

Some authors recommended that injecting a single bolus at the point where the subclavian artery meets the first rib (corner pocket technique) [21]. This technique is thought to result in more reliable blockade of the inferior divisions of the brachial plexus. However, Duggan et al. [3] and Tran et al. [4] could not reduce the volume of local anesthetic even though they used the corner pocket technique. Therefore, we think that the corner pocket technique cannot reduce the local anesthetic volume effectively.

Before the beginning of the study, we were curious why these previous studies could not reduce the effective local anesthetic volume even though they used ultrasound, because local anesthetic volume could be reduced in other peripheral nerve blocks with ultrasound guidance [5-8]. Therefore, we reviewed several articles related to ultrasound-guided nerve blocks $[1,2,9,12-15]$. Among them, we found an idea in a study by Bigeleisen et al. [9]. They achieved a $100 \%$ success rate with 20 $\mathrm{ml}$ of $1 \%$ lidocaine in ultrasound-guided supraclavicular block. They injected local anesthetic around the deeper parts of the

Table 2. Block Performance Data

\begin{tabular}{lc}
\hline Onset time (min) & $17.2 \pm 5.7$ \\
Adverse effects & $18(60.0)$ \\
Paresthesia & $0(0.0)$ \\
Vascular puncture & $7(23.3)$ \\
Horner's syndrome & $0(0.0)$ \\
Voice change & $1(3.3)$ \\
Chest discomfort & $1(3.3)$ \\
Hemidiaphragmatic paresis &
\end{tabular}

Values are mean \pm SD or number of patients (\%). 
brachial plexus. However injection was performed intraneurally, which has been known to produce neurological complications [10,11].

Based on this, we tried to design a technique which could reduce the local anesthetic volume. As a result, we assumed the combination of location the needle near the lower trunk and multiple injections with withdrawing the needle was a possible way to spread local anesthetic around the three trunks using a smaller volume of local anesthetic.

However, we did not trust Bigeleisen et al's approach [9] completely. We were also worried about the nerve puncture or intraneural injection. Therefore, we advanced and withdrew the needle in zigzags to avoid nerve puncture. In addition, we also confirmed that the location of the needle tip was not in hypoechoic nodules (in nerves) before each injection. For further safety, we injected $0.5 \mathrm{ml}$ of local anesthetic as a test dose. If the patients complained of paresthesia or pain, or the injection pressure was high, or the spread of local anesthetic was not visualized, we stopped injection, and withdrew the needles and tried again. We regarded the paresthesia or pain, or high injection pressure as intraneural injection $[10,11]$.

Of course, we did not think that these careful manipulations always guaranteed safety $[22,23]$. Therefore, we were not completely free from the possibility of nerve puncture or intraneural injection. However, nerve puncture or intraneural injection does not always lead to a neurological injury. No neurological complications occur even though the nerve puncture and intraneural injection were apparent $[9,24,25]$. Neurological complications occur by a combination of intraneural injection and high injection pressure, because high intraneural pressure has been believed to cause ischemic injury to the nerve $[10,11]$. Nerve damage also occurs when the fascicle, which is enveloped by perineurium, is damaged $[9,24,25]$. However, it is difficult for a short beveled needle to penetrate perineurium because the perineum is tough and mechanically resistant [25]. Therefore, we believe that advancing the needle through brachial plexus is relatively safe. In fact, we observed no neurological complications in our study.

During the study, we found that the difficulty of needle advancement was variable among the patients. In some patients, the needle advancement was very difficult. There seemed to be some invisible barriers which blocked the needle advancement even though the needle located in free space between nerves on ultrasound image. The local anesthetic did not spread freely between divisions in these cases. Most failed cases fell in this situation. We think there is individual variance of density of connective tissue between nerve divisions. Therefore, we assume that the connective tissue is loose in some patients or dense in other patients. However, further study should be performed to confirm this.

We also checked and evaluated other complications, particularly dyspnea by hemidiaphragmatic paresis. We observed the possibility of decreased incidence of hemidiaphragmatic paresis in supraclavicular block with a lower local anesthetic volume. Only one patient who received $21 \mathrm{ml}$ of local anesthetic complained of chest discomfort and showed hemi-diaphragmatic paresis on the post-operative chest X-ray. No hemidiaphragmatic paresis was observed in the patients who received a local anesthetic volume $<21 \mathrm{ml}$. Previous studies have reported a 35-60\% incidence of hemi-diaphragmatic paresis after supraclavicular block using typical volumes of local anesthetics [26-29].

Hemi-diaphragmatic paresis does not always result in symptoms as dyspnea. However dyspnea may occur in the patients with compromised functional residual capacity such as those with older age, pregnancy, or morbid obesity [30]. Therefore, applying a supraclavicular block with a lower volume of local anesthetic can be considered for these patients.

This study has several limitations. First, DUDM is designed to calculate the MEV with only a limited number. Therefore, some authors recommended that studies should have 20 or more patients for accuracy $[18,19]$. Thus we recruited 30 patients in this study. However, we still think it has a limitation even though we used more patients than they recommended. Second, all blocks were performed by an experienced operator and an assistant. We advanced and withdrew the needle in zigzags to avoid nerve puncture while approaching to the lower trunk of brachial plexus. This technique needs much experience of brachial plexus blocks. Therefore, this result cannot be applied to general anesthesiologists. Third, the follow-up for neurological complications was limited. About 1 to 1.5 month follow-up was performed by an orthopedic surgeon in the outpatient department. Therefore delayed neurological complications cannot be excluded.

In conclusion, estimated minimum local anesthetic volume for ultrasound-guided supraclavicular block in 95, 90, and 50\% of patients were 17,15 , and $9 \mathrm{ml}$, respectively. However, the location of the needle near the lower trunk of brachial plexus and multiple injections withdrawing the needle should be performed to achieve these results, and very careful injection by a skillful operator is required. 


\section{References}

1. Perlas A, Lobo G, Lo N, Brull R, Chan VW, Karkhanis R. Ultrasound-guided supraclavicular block: outcome of 510 consecutive cases. Reg Anesth Pain Med 2009; 34: 171-6.

2. Kapral S, Krafft P, Eibenberger K, Fitzgerald R, Gosch M, Weinstabl C. Ultrasound-guided supraclavicular approach for regional anesthesia of the brachial plexus. Anesth Analg 1994; 78: 507-13.

3. Duggan E, El Beheiry H, Perlas A, Lupu M, Nuica A, Chan VW, et al. Minimum effective volume of local anesthetic for ultrasound-guided supraclvicular brachial plexus block. Reg Anesth Pain Med 2009; 34: 215-8.

4. Tran de QH, Dugani S, Correa JA, Dyachenko A, Alsenosy N, Finlayson RJ. Minimum effective volume of lidocaine for ultrasound-guided supraclavicular block. Reg Anesth Pain Med 2011; 36: 466-9.

5. Marhofer P, Schrogendorfer K, Wallner T, Koinig H, Mayer N, Kapral S. Ultrasonographic guidance reduces the amount of local anesthetic for 3-in-1 blocks. Reg Anesth Pain Med 1998; 23: 584-8.

6. Casati A, Baciarello M, Di Cianni S, Danelli G, De Marco G, Leone S, et al. Effects of ultrasound guidance on the minimum effective anaesthetic volume required to block the femoral nerve. Br J Anaesth 2007; 98: 823-7.

7. O'Donnell BD, Ryan H, O'Sullivan O, Iohom G. Ultrasound-guided axillary brachial plexus block with 20 milliliters local anesthetic mixture versus general anesthesia for upper limb trauma surgery: an observer-blinded, prospective, randomized, controlled trial. Anesth Analg 2009; 109: 279-83.

8. Harper GK, Stafford MA, Hill DA. Minimum volume of local anaesthetic required to surround each of the constituent nerves of the axillary brachial plexus, using ultrasound guidance: a pilot study. Br J Anaesth 2010; 104: 633-6.

9. Bigeleisen PE, Moayeri N, Groen GJ. Extraneural versus intraneural stimulation thresholds during ultrasound-guided supraclavicular block. Anesthesiology 2009; 110: 1235-43.

10. Selander D, Edshage S, Wolff T. Paresthesiae or no paresthesiae? Nerve lesions after axilary blocks. Acta Anaesthesiol Scand 1979; 23: 27-33.

11. Hadzic A, Diberovic F, Shah S, Kulenovic A, Kapur E, Zaciragic A, et al. Combination of intraneural injection and high injection pressure leads to fascicular injury and neurologic deficits in dogs. Reg Anesth Pain Med 2004; 29: 417-23.

12. Williams SR, Chouinard P, Arcand G, Harris P, Ruel M, Boudreault D, et al. Ultrasound guidance speeds execution and improves the qualilty of supraclavicular block. Anesth Analg 2003; 97: 1518-23.

13. Chan VW, Perlas A, Raw R, Odukoya O. Ultrasound-guided supraclavicular brachial plexus block. Anesth Analg 2003; 97 : 1514-7.

14. Arcand G, William SR, Chouinard P, Boudreault D, Harris P, Ruel M, et al. Ultrasound-guided infraclavicular block versus supraclavicular block. Anesth Analg 2005; 101: 886-90.

15. Subramanyam R, Vaishnav V, Chan VW, Brown-Shreves D, Brull R. Lateral versus medial needle approach for ultrasound-guided supraclavicular block: a randomized controlled trial. Reg Anesth Pain Med 2011; 36: 387-92.

16. Dixon WJ, Massey FJ. Introduction to statistical analysis. 4th ed. New York, McGraw-Hill. 1983, pp 377-94.

17. Dixon WJ. Staircase bioassay: the up-and-down method. Neurosci Biobehav Rev 1991; 15: 47-50.

18. Pace NL, Stylianou MP. Advances in and limitations of up-and-down methodology. Anesthesiology 2007; 107: 144-52.

19. Fisher D. What if half of your patients moved (or remembered or did something else bad) at incision? Anesthesiology 2007; 107: 1-2.

20. Hadzic A, Carrera A, Clark T, Gadsden N, Karmakar M, Sala-Blanch X, et al. Hadzic's pheripheral nerve blocks and anatomy for ultrasoundguided regional anesthesia. 2nd ed. New York, McGraw-Hill. 2012, pp 362-7.

21. Soares LG, Brull R, Lai J, Chan VW. Eight ball, corner pocket: the optimal needle position for ultrasound-guided supraclavicular block. Reg Anesth Pain Med 2007; 32: 94-5.

22. Liu SS, YaDeau JT, Shaw PM, Wilfred S, Shetty T, Gordon M. Incidence of unintentional intraneural injection and postoperative neurological complications with ultrasound-guided interscalene and supraclavicular nerve blocks. Anaesthesia 2011; 66: 168-74.

23. Tsai TP, Vuckovic I, Dilberovic F, Obhodzas M, Kapur E, Divanovic KA, et al. Intensity of the stimulating current may not be a reliable indicator of intraneural needle placement. Reg Anesth Pain Med 2008; 33: 207-10.

24. Bigeleisen PE. Nerve puncture and apparent intraneural injection during ultrasound-guided axillary block does not invariably result in neurologic injury. Anesthesiology 2006; 105: 779-83.

25. Selander D, Brattsand R, Lundborg G, Nordborg C, Olsson Y. Local anesthetics: importance of mode of application, concentration and adrenaline for the appearance of nerve lesions. An experimental study axonal degeneration and barrier damage after intrafascicular injection or topical application of bupivacaein (Marcaine). Acta Anaesthesiol Scand 1979; 23: 127-36.

26. Farrar MD, Scheybani M, Nolte H. Upper extremity block, effectiveness and complications. Reg Anesth 1981; 6: 133-4.

27. Neal JM, Moore JM, Kopacz DJ, Liu SS, Kramer DJ, Plorde JJ. Quantitative analysis of respiratory, motor, and sensory function after supraclavicular block. Anesth Analg 1998; 86: 1239-44.

28. Pham-Dang C, Gunst JP, Gouin F, Poirier P, Touchais S, Meunier JF, et al. A novel supraclavicular approach to brahchial plexus block. Anesth Analg 1997; 85: 111-6.

29. Cornish PB, Leaper CJ, Nelson G, Anstis F, McQuillan C, Stienstra R. Avoidance of phrenic nerve paresis during continuous supraclavicular regional anaesthesia. Anaesthesia 2007; 62: 354-8.

30. Song JG, Kim SK, Jeon DG, Kwon MA, Yoo JH. Dyspnea after supraclavicular block in a morbidly obese patient due to phrenic nerve palsy. Korean J Anesthesiol 2009; 57: 511-4. 